\title{
REVIEW
}

\section{Decision-Making in Clinical Practice: Oral Anticoagulant Therapy in Patients with Non-valvular Atrial Fibrillation and a Single Additional Stroke Risk Factor}

Tatjana S. Potpara $\cdot$ Nikolaos Dagres $\cdot$ Nebojša Mujović $\cdot$

Dragan Vasić • Milika Ašanin • Milan Nedeljkovic · Francisco Marin ·

Laurent Fauchier - Carina Blomstrom-Lundqvist · Gregory Y. H. Lip

Received: November 2, 2016 / Published online: December 8, 2016

(c) The Author(s) 2016. This article is published with open access at Springerlink.com

\section{ABSTRACT}

Approximately 1 in $3-4$ patients presenting with an ischemic stroke will also have atrial fibrillation (AF), and AF-related strokes can be effectively prevented using oral anticoagulant therapy (OAC), either with well-controlled vitamin $\mathrm{K}$ antagonists (VKAs) or non-vitamin

Enhanced content To view enhanced content for this article go to http://www.medengine.com/Redeem/F037 F0603360C923.

T. S. Potpara $(\bowtie) \cdot$ N. Mujović · M. Ašanin ·

M. Nedeljkovic · G. Y. H. Lip

School of Medicine, Belgrade University, Belgrade, Serbia

e-mail: tatjana.potpara@mfub.bg.ac.rs;

tanjapotpara@gmail.com

T. S. Potpara · N. Mujović · M. Ašanin .

M. Nedeljkovic

Cardiology Clinic, Clinical Centre of Serbia,

Belgrade, Serbia

\section{N. Dagres}

Department of Electrophysiology, Heart Center

Leipzig, Leipzig, Germany

D. Vasić

Vascular Surgery Clinic, Clinical Centre, Belgrade, Serbia

F. Marin

Department of Cardiology, Hospital Universitario

Virgen de la Arrixaca, IMIB-Arrixaca, Murcia, Spain
$\mathrm{K}$ antagonist oral anticoagulants (NOACs). In addition, OAC use (both VKAs and NOACs) is associated with a $26 \%$ reduction in all-cause mortality (VKAs) or an additional 10\% mortality reduction with NOACs relative to VKAs. The decision to use OAC in individual AF patient is based on the estimated balance of the benefit from ischemic stroke reduction against the risk of major OAC-related bleeding [essentially intracranial hemorrhage (ICH)]. Better appreciation of the importance of VKAs'

\section{Fauchier}

Service de Cardiologie, Centre Hospitalier

Universitaire Trousseau et Faculte de Medecine, Universite Francois Rabelais, Tours, France

C. Blomstrom-Lundqvist

Department of Cardiology, Institution of Medical

Science, Uppsala University, Uppsala, Sweden

G. Y. H. Lip

University of Birmingham Institute of

Cardiovascular Science, City Hospital, Birmingham, UK

G. Y. H. Lip

Aalborg Thrombosis Research Unit, Department of Clinical Medicine, Aalborg University, Aalborg,

Denmark 
anticoagulation quality [a target time in therapeutic range (TTR) of $\geq 70 \%$ ] and the availability of NOACs (which offer better safety compared to VKAs) have decreased the estimated threshold for OAC treatment in AF patients towards lower stroke risk levels. Still, contemporary registry-based data show that $\mathrm{OAC}$ is often underused in $\mathrm{AF}$ patients at increased risk of stroke. The uncertainty whether to use OAC may be particularly pronounced in AF patients with a single additional stroke risk factor, who are often (mis)perceived as having a "borderline" or insufficient stroke risk to trigger the use of OAC. However, observational data from real-world AF cohorts show that the annual stroke rates in such patients are higher than in patients with no additional stroke risk factors, and OAC use has been associated with reduction in stroke, systemic embolism, or death in comparison to no therapy or aspirin, with no increase in the risk of bleeding relative to aspirin. In this review article, we summarize the basic principles of stroke risk stratification in AF patients and discuss contemporary real-world evidence on OAC use and outcomes of OAC treatment in AF patients with a single additional stroke risk factor in various real-world AF cohorts.

Keywords: Atrial fibrillation; Non-valvular atrial fibrillation; Non-vitamin $\mathrm{K}$ antagonist; Oral anticoagulants; Stroke prevention; Stroke risk assessment; Stroke risk factor; Stroke risk scores; Vitamin K antagonist

\section{INTRODUCTION}

Atrial fibrillation (AF) currently affects at least 33.5 million adults in the world population, not including subclinical or undiagnosed AF cases
$[1,2]$, and the global prevalence of documented AF is probably underestimated because of limited data outside Europe and North America [1, 3].

Recent population-based studies and stroke registries consistently report a substantial AF-attributable risk of stroke, particularly in the elderly [4]. Approximately 1 in 3-4 patients presenting with an ischemic stroke will also have AF (either already known or first diagnosed at the time of acute stroke, or documented during the post-stroke monitoring) [4, 5]. In comparison to strokes from other causes, AF-related strokes are more often fatal or associated with greater permanent neurological deficit [6], but can be effectively prevented using oral anticoagulant therapy (OAC) with well-controlled vitamin $\mathrm{K}$ antagonists (VKAs) [7] or non-vitamin K antagonist oral anticoagulants (NOACs) apixaban [8], rivaroxaban [9], dabigatran [10], or edoxaban [11]. The use of OAC is also associated with significant reduction in all-cause mortality in AF patients, by $26 \%$ with VKAs vs. control/placebo [7], and by additional $10 \%$ risk reduction with NOACs relative to warfarin according to meta-analysis [12].

The decision to use $\mathrm{OAC}$ in individual $\mathrm{AF}$ patient is based on the estimated balance of the benefit from ischemic stroke reduction against the risk of major OAC-related bleeding [essentially intracranial hemorrhage (ICH)]. Better appreciation of the importance of VKAs' anticoagulation quality [a target time in therapeutic range (TTR) of $\geq 70 \%$ ] and the availability of NOACs (which offer better safety compared to VKAs) [12] have decreased the estimated threshold for OAC treatment in AF patients from $1.7 \%$ (as estimated for the VKAs standard treatment) to $0.9 \%$ annual stroke risk, assuming that NOACs are available [13]. 
Still, contemporary registry-based data show that OAC is often underused in AF patients at increased risk of stroke [14-18]. The uncertainty whether to use OAC may be particularly pronounced in $\mathrm{AF}$ patients with a single additional stroke risk factor, who are often (mis)perceived as having a "borderline" or insufficient stroke risk to trigger the use of OAC. Also, there is some inconsistency in formal $\mathrm{AF}$ guidelines regarding the use of $\mathrm{OAC}$ in this subset of AF patients, as shown in Table 1 [19-25].

In this review article, we summarize the basic principles of stroke risk stratification in AF patients and discuss contemporary real-world evidence on OAC use and outcomes of OAC treatment in AF patients with a single additional stroke risk factor in various real-world AF cohorts. This article is based on previously conducted studies and does not involve any new studies of human or animal subjects performed by any of the authors.

\section{STROKE RISK STRATIFICATION AND THROMBOPROPHYLAXIS IN PATIENTS WITH ATRIAL FIBRILLATION}

Patients with AF have an excessive risk of stroke compared to their counterparts without AF but individual stroke risk is not homogeneous and depends on the presence (or absence) of various stroke risk factors [26]. To facilitate the assessment of AF-related risk of stroke in clinical practice, established clinical stroke risk factors derived from the control or placebo arms of historical trials on stroke prevention in AF [7] or large observational AF cohorts have been combined into various stroke risk scores, such as the $\mathrm{CHADS}_{2}$ or $\mathrm{CHA}_{2} \mathrm{DS}_{2}$-VASc score [27] (Table 2), the latter being more inclusive of relevant clinical stroke risk factors in comparison to the $\mathrm{CHADS}_{2}$ score $[28,29]$. Although simple, the $\mathrm{CHADS}_{2}$ score has well-recognized limitations [30] including poor identification of AF patients at truly low risk of stroke. For example, it has been shown that patients with a $\mathrm{CHADS}_{2}$ of 0 (presumably low-risk patients) have had an annual stroke rate as high as $3.2 \%$ [28].

The $\mathrm{CHA}_{2} \mathrm{DS}_{2}$-VASc score has been validated in a number of independent cohorts $[28,31-35]$, and is the recommended tool for stroke risk assessment in most of the latest formal AF guidelines [20, 24]. Compared to other AF-related stroke risk scores, $\mathrm{CHA}_{2} \mathrm{DS}_{2}$-VASc is reasonably simple, which is necessary for widespread use in routine clinical practice, and performs well, especially in reliable identification of AF patients at truly low risk of stroke (i.e., those with no additional stroke risk factors) who do not need any thromboprophylaxis [28, 36-39]. Recent comparisons of the more complex ATRIA score against the $\mathrm{CHA}_{2} \mathrm{DS}_{2}$-VASc score yielded conflicting results, although $\mathrm{CHA}_{2} \mathrm{DS}_{2}$-VASc generally outperforms the ATRIA score for risk prediction [35, 37, 40, 41]. Of note, the ATRIA score includes the indices of renal function (i.e., estimated glomerular filtration rate and proteinuria), which may not be readily available in a busy outpatient clinic or hospital ward, and uses a complicated 10-year graded scale for age to calculate the score value separately for patients with and without prior stroke or TIA [38].

Adding in various biomarkers [e.g., biomarkers of cardiac function such as cardiac troponin or N-terminal fragment B-type natriuretic peptide (NT-proBNP)] [42, 43] or various cardiac imaging modalities (e.g., left atrial size, morphology and function, left atrial fibrosis) [44] has been shown to improve the predictive value of clinical risk factor based 


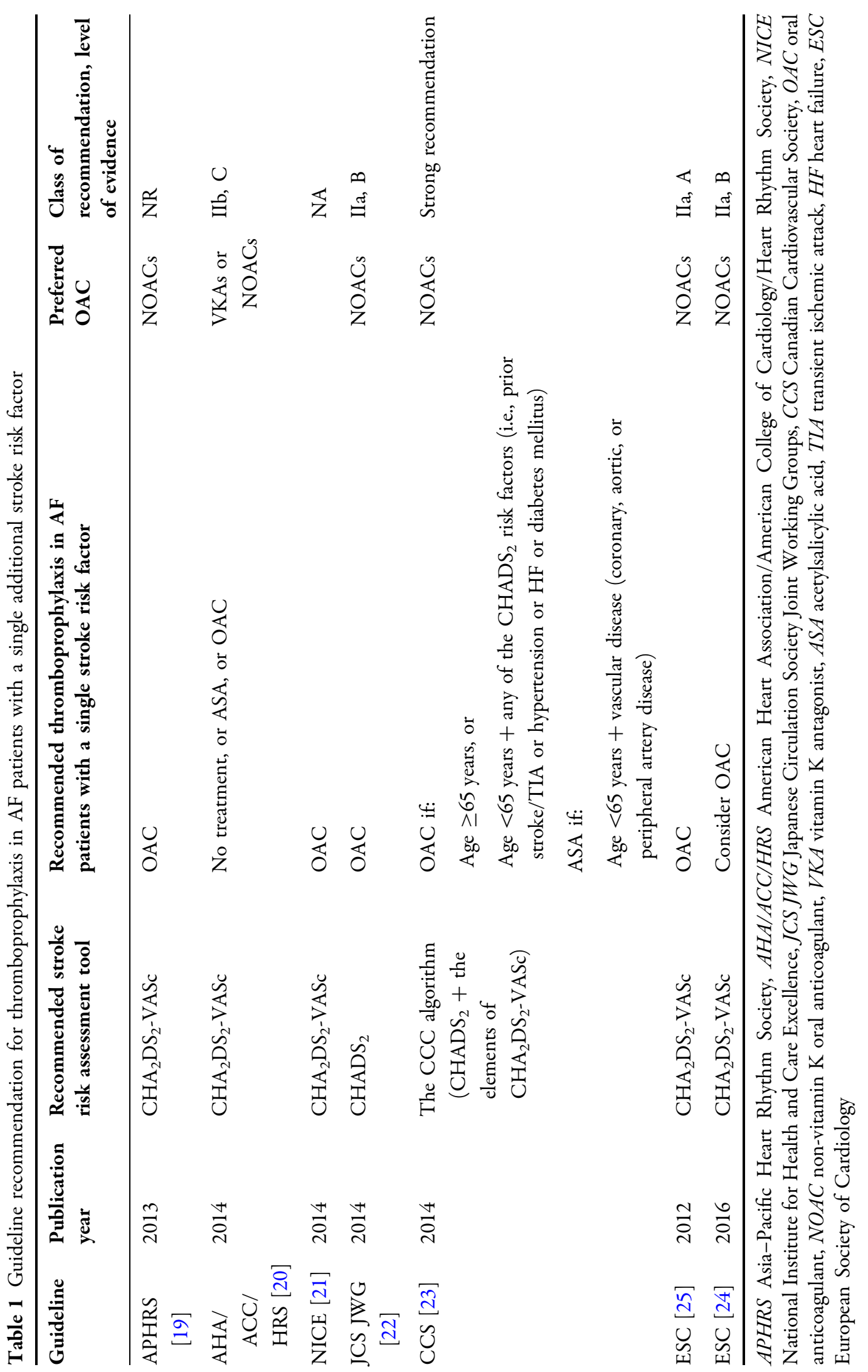




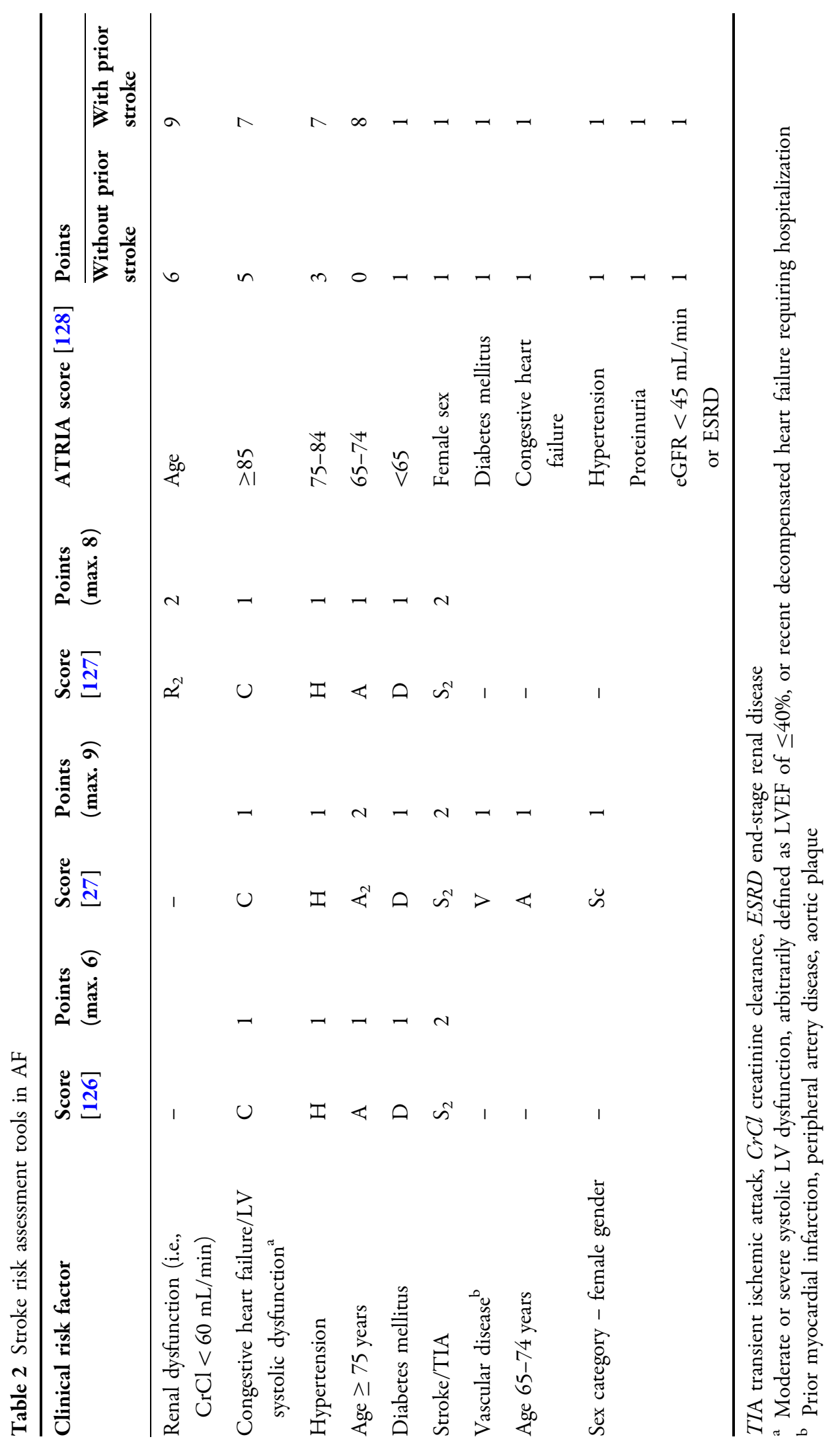


scores such as the $\mathrm{CHA}_{2} \mathrm{DS}_{2}$-VASc score, but mainly by further substratification of high-risk patients as identified by the "classic" $\mathrm{CHA}_{2} \mathrm{DS}_{2}$-VASc score. Since the $\mathrm{CHA}_{2} \mathrm{DS}_{2}$-VASc $\geq 2$ patients already have a clear indication for OAC $[20,23,24]$, further quantification of their stroke risk would not really influence clinical decision-making and is of little practical value. Nevertheless, in selected AF patients without "classical" $\mathrm{CHA}_{2} \mathrm{DS}_{2}$-VASc stroke risk factors (e.g., a 56-year-old man with a family history of stroke) or those in whom the estimated risk of bleeding apparently exceeds the risk of stroke (e.g., in AF patients with a single additional stroke risk factor and a prior bleeding event, or taking dual antiplatelet therapy post acute coronary syndrome), a refinement in stroke risk assessment using biomarkers and/or imaging modalities could possibly inform the decision to use OAC. However, more research is needed to define the biomarker cutoff values and the time course of blood sampling which would be informative for stroke risk assessment in clinical practice [45].

Female sex-related risk of stroke in $\mathrm{AF}$ has been extensively debated. In a large meta-analysis, which included 30 studies with a total of nearly 4.5 million participants, the presence of $\mathrm{AF}$ in female individuals has been associated with greater relative risk of stroke, all-cause mortality, and cardiovascular outcomes compared to men [46]. However, the risk of stroke in women with $\mathrm{AF}$ has been shown to be age-dependent. Whilst younger female individuals with AF had similar or even lower risk of stroke compared to their age-matched male counterparts, elderly female AF patients were at higher risk of stroke than the age-matched male patients [47-51]. Possible mechanisms of sex-related differences in the risk of AF-related stroke are still not fully elucidated [52].
Female sex has been assigned 1 point in the $\mathrm{CHA}_{2} \mathrm{DS}_{2}$-VASc score [27]. Hence, a female AF patient without additional $\mathrm{CHA}_{2} \mathrm{DS}_{2}$-VASc stroke risk factors will have a score of 1 , but should be treated the same as male AF patients with a $\mathrm{CHA}_{2} \mathrm{DS}_{2}$-VASc score of $0[20,24,25]$. These truly low risk AF patients (i.e., men with $\mathrm{CHA}_{2} \mathrm{DS}_{2}$-VASc $=0$ and women with $\mathrm{CHA}_{2} \mathrm{DS}_{2}$-VASc $=1$ ) have low annual stroke rates of $\leq 1 \% \quad[32,53]$ and the use of antithrombotic therapies in such patients has been associated with a neutral or negative relationship with stroke, bleeding, or death in several large cohorts [54-57].

\section{"REAL-WORLD" RATES OF STROKE IN NON-ANTICOAGULATED PATIENTS WITH ATRIAL FIBRILLATION AND ONE ADDITIONAL STROKE RISK FACTOR}

Figure 1 shows the annual rates of stroke in AF patients without additional stroke risk factors (i.e., with a $\mathrm{CHA}_{2} \mathrm{DS}_{2}$-VASc score of 0 [men] or 1 [women]) and in those with a single additional stroke risk factor, as observed in various real-world AF cohorts. In most of the studies stroke rates are significantly increased with the presence of one additional stroke risk factor in non-anticoagulated AF patients.

Annual stroke rates in AF patients with a single additional stroke risk factor observed in these $[37,54,56,58-61]$ and other observational cohorts [31, 33, 35, 57, 62-67] are shown in Table 3. Overall, the stroke rates ranged from $0.5 \%$ to $2.75 \%$, or to $6.60 \%$ in the study with the highest annual stroke rate (Table 3). Such variability in stroke rates most probably results from variable methodology, anticoagulation status, and outcome definitions in the studies [30, 68]. For example, the study by Suzuki et al. was based 


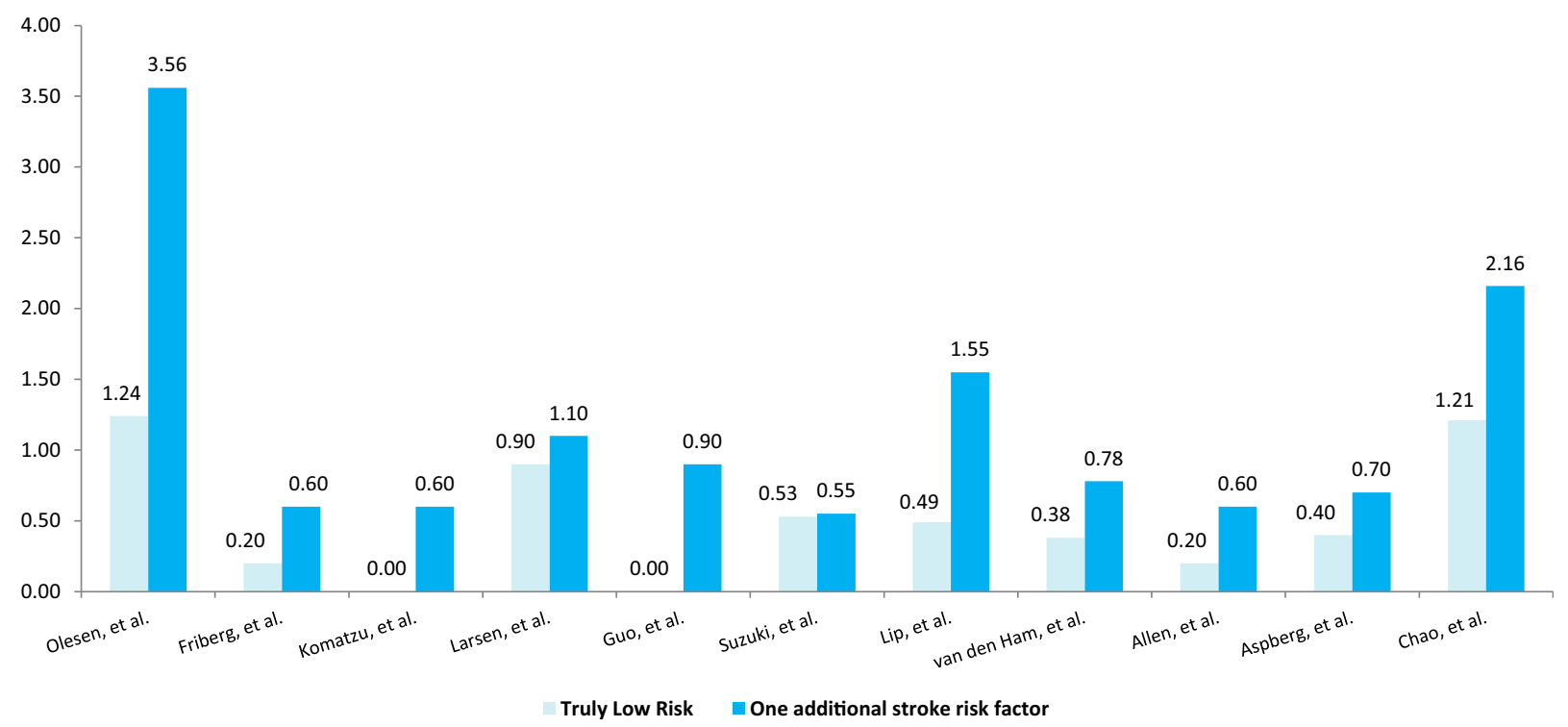

Fig. 1 Real-world stroke rates in AF patients with and without a single additional stroke risk factor [31, 33, 35, 41, 54, 56, 57, 59-61, 67, 129]. Komatsu et al. and Suzuki et al. reported stroke rates based on no OAC at baseline, but there was no record on whether OAC treatment was started during follow-up (hence, the

on non-OAC use at baseline, but OAC status at follow-up was unknown, such that the unusually low stroke event rate could be related to some high-risk patients being started on OAC during follow-up [61].

Friberg et al. showed how variable duration of "blanking period" influenced the observed stroke rates (overall, the ischemic stroke rate was $5.4 \%$ with no quarantine period, $3.0 \%$ with 1-week blanking period, and $2.8 \%$ with a 4-week quarantine, which was ultimately used in that study) [66]. Although registry-based studies generally require a quarantine period (during which the events are not counted) to achieve a stable population for long-term follow-up, there is no room for a quarantine period in clinical practice, because the decision to use OAC should be made immediately upon the documentation of AF rather than several weeks or months later. reported stroke rates may be artificially low). Friberg et al. and Aspberg et al. reported stroke rates only in AF patients who were never prescribed $\mathrm{OAC}$, starting from baseline throughout the follow-up (i.e., a conditioning on the future)

The event rate in the aforementioned study by Friberg et al. was also influenced by the definition of thromboembolic outcome-it was doubled (from 0.5 to $0.7 \%$ to $1.3 \%$ ) when the outcome of ischemic stroke was combined with non-specified stroke, transient ischemic attack (TIA), or systemic embolism [66]. As a result of a low annual rate of ischemic stroke among AF patients with a single additional stroke risk factor in that study $(0.5 \%)$ the authors questioned the benefit of OAC in such patients, thus neglecting the importance of reducing other AF-related outcomes such as mortality or systemic embolism. In addition, the study has been criticized for "conditioning on the future", since all patients ever given OAC (including the follow-up) were excluded from the analysis, thus introducing a potential selection bias leading to low event rates. The same methodological flaws with "conditioning 
Table 3 Rates of stroke in non-anticoagulated "real-world" AF patients with single additional stroke risk factor

\begin{tabular}{|c|c|c|c|c|}
\hline Study & $\begin{array}{l}\text { Publication } \\
\text { year }\end{array}$ & Dataset & $\begin{array}{l}N \text { of events per } N \text { of } \\
\text { patients or patient-years }\end{array}$ & $\begin{array}{l}\text { Annual event rate }(95 \% \\
\text { confidence interval) }\end{array}$ \\
\hline $\begin{array}{l}\text { Olesen et al. } \\
{[31]}\end{array}$ & 2011 & $\begin{array}{l}\text { Danish nationwide administrative } \\
\text { databases }\end{array}$ & $\mathrm{NR} / 14,526$ & $2.01(1.70-2.36)$ \\
\hline $\begin{array}{l}\text { Friberg et al. } \\
{[63]}\end{array}$ & 2012 & $\begin{array}{l}\text { Swedish National Hospital } \\
\text { Discharge Registry }\end{array}$ & $\mathrm{NR} / 6770$ & $\begin{array}{l}0.6(\mathrm{NR}) \\
0.9(\mathrm{NR})\end{array}$ \\
\hline $\begin{array}{l}\text { Friberg et al. } \\
{[56]}\end{array}$ & 2012 & $\begin{array}{l}\text { Swedish National Hospital } \\
\text { Discharge Registry }\end{array}$ & $63 / 10,500 \mathrm{PY}$ & $0.60(0.45-0.77)$ \\
\hline $\begin{array}{l}\text { Komatzu } \\
\text { et al. [59]* }\end{array}$ & 2012 & $\begin{array}{l}\text { A retrospective Japanese paroxysmal } \\
\text { AF cohort }\end{array}$ & 1/210 PY & $0.62(0.00-3.23)$ \\
\hline $\begin{array}{l}\text { Larsen et al. } \\
\quad[60]\end{array}$ & 2012 & $\begin{array}{l}\text { The Prospective Danish Diet, } \\
\text { Cancer, and Health Cohort Study }\end{array}$ & 25/2273 PY & $1.10(0.65-1.63)$ \\
\hline $\begin{array}{l}\text { Guo et al. } \\
\text { [33] }\end{array}$ & 2013 & $\begin{array}{l}\text { The Chinese PLA General Hospital } \\
\text { medical database }\end{array}$ & $\mathrm{NR} / 114$ & $0.9(\mathrm{NR})$ \\
\hline $\begin{array}{l}\text { Huang et al. } \\
\text { [58] }\end{array}$ & 2014 & The Hong Kong AF cohort & 70/1061 PY & $6.60(5.09-8.29)$ \\
\hline $\begin{array}{l}\text { Forslund } \\
\text { et al. [64] }\end{array}$ & 2014 & $\begin{array}{l}\text { The Stockholm (Sweden) AF } \\
\text { Database, } n=41,810\end{array}$ & NR & $0.5(\mathrm{NR})$ \\
\hline $\begin{array}{l}\text { Chao et al. } \\
\text { [37] }\end{array}$ & 2014 & $\begin{array}{l}\text { The National Health Insurance } \\
\text { research database in Taiwan }\end{array}$ & $2312 / 110,854$ & $2.09(2.00-2.17)$ \\
\hline $\begin{array}{l}\text { Suzuki et al. } \\
{[61]^{*}}\end{array}$ & 2015 & $\begin{array}{l}\text { The Shinken database, J-RHYTHM } \\
\text { and Fushimi AF Registries }\end{array}$ & 6/1096 PY & $0.55(0.04-1.23)$ \\
\hline $\begin{array}{l}\text { Olesen et al. } \\
{[62]}\end{array}$ & 2015 & $\begin{array}{l}\text { Danish nationwide administrative } \\
\text { databases }\end{array}$ & 697/40,023 PY & $1.68(1.46-1.94)$ \\
\hline $\begin{array}{l}\text { Chao et al. } \\
{[65]}\end{array}$ & 2015 & $\begin{array}{l}\text { The National Health Insurance } \\
\text { research database in Taiwan }\end{array}$ & $\begin{array}{l}1858 / 67,673 \text { PY (m) } \\
1174 / 46,058 \text { PY (f) }\end{array}$ & $\begin{array}{l}2.75(2.62-2.87) \mathrm{m} \\
2.55(2.41-2.70) \mathrm{f}\end{array}$ \\
\hline $\begin{array}{l}\text { Lip et al. } \\
\text { [57] }\end{array}$ & 2015 & $\begin{array}{l}\text { Danish nationwide administrative } \\
\text { databases }\end{array}$ & $129 / 8573$ & $1.50(\mathrm{NR})$ \\
\hline $\begin{array}{l}\text { Friberg et al. } \\
{[66]^{\dagger}}\end{array}$ & 2015 & $\begin{array}{l}\text { The Swedish nationwide health } \\
\text { registries }\end{array}$ & $\mathrm{NR} / 12,298$ & $0.5(\mathrm{NR})$ \\
\hline $\begin{array}{l}\text { van den } \\
\text { Ham et al. } \\
{[35]}\end{array}$ & 2015 & $\begin{array}{l}\text { The Clinical Practice Research } \\
\text { Datalink database (UK) }\end{array}$ & 130/16,800 PY & $0.78(\mathrm{NR})$ \\
\hline $\begin{array}{l}\text { Allen et al. } \\
\text { [67] }\end{array}$ & 2016 & $\begin{array}{l}\text { Linked UK primary and secondary } \\
\text { healthcare databases }\end{array}$ & 153/224,777 PY & $0.6(0.5-0.7)$ \\
\hline
\end{tabular}


Table 3 continued

\begin{tabular}{lllll}
\hline Study & $\begin{array}{l}\text { Publication } \\
\text { year }\end{array}$ & Dataset & $\begin{array}{l}\text { Nof events per } \boldsymbol{N} \text { of } \\
\text { patients or patient-years }\end{array}$ & $\begin{array}{l}\text { Annual event rate (95\% } \\
\text { confidence interval) }\end{array}$ \\
\hline $\begin{array}{l}\text { Aspberg } \\
\text { et al. }[41]^{\dagger}\end{array}$ & 2016 & $\begin{array}{r}\text { The National Patient Register and } \\
\text { Prescribed Drug Register, Sweden }\end{array}$ & $337 / 45,581.6 \mathrm{PY}$ & 0.7 (NR) \\
\hline
\end{tabular}

$P Y$ patient-years, $N R$ not reported, $U K$ United Kingdom, $m$ male, $f$ female

* Komatsu et al. and Suzuki et al. reported stroke rates based on no OAC at baseline, but there was no record on whether OAC treatment was started during follow-up (hence, the reported stroke rates may be artificially low)

$\dagger$ Friberg et al. and Aspberg et al. reported stroke rates only in AF patients who were never prescribed OAC, starting from baseline throughout the follow-up (i.e., a conditioning on the future)

on the future" were apparent in the paper by Aspberg et al. [41]. A more appropriate assessment should be censoring on OAC initiation, as reported by Nielsen et al. [69].

In another study, which used the outcome of ischemic stroke or systemic embolism, the rates of ischemic stroke and mortality in untreated AF patients without additional stroke risk factors were $0.43 \%$ and $3.87 \%$, respectively, whilst the rates in untreated AF patients with a single additional stroke risk factor were $1.50 \%$ (ischemic stroke) and $11.30 \%$ (death) [57]. Thus, the presence of a single additional stroke risk factor in non-anticoagulated AF patients was associated with a threefold increase in 1-year risk of stroke [hazard ratio (HR) 3.8; 95\% confidence interval (CI), 2.61-5.63] and a threefold increase in the risk of death (HR 3.23; 95\% CI 2.87-3.63) in comparison to untreated AF patients without additional stroke risk factors [57].

A meta-analysis of seven large observational studies yielded a $1.61 \%(0.00-3.23 \%)$ annual risk of ischemic stroke in AF patients with one additional stroke risk factor [53], which is slightly below the $1.7 \%$ annual stroke risk threshold for the use of VKAs but well above the $0.9 \%$ cutoff for NOACs use [13]. The wide confidence interval in that meta-analysis resulted from considerable heterogeneity among the studies. Nevertheless, removing the study with the highest annual stroke risk of $6.60 \%$ from the meta-analysis [58] still yielded a $0.87 \%(0.28-1.46 \%)$ annual stroke risk, which was still around the threshold for NOACs use.

Several studies showed that different stroke risk factors within the $\mathrm{CHA}_{2} \mathrm{DS}_{2}$-VASc score carry different weight with respect to stroke rates $[35,58,65,70]$ (Table 4). In the study from Taiwan, for example, stroke rates among AF patients with a single additional stroke risk factor varied from $1.91 \%$ with hypertension to $3.34 \%$ with age of 65-74 years [65]. In all studies, age has been consistently identified as the most powerful single stroke risk factor among $\mathrm{AF}$ patients with a $\mathrm{CHA}_{2} \mathrm{DS}_{2}$-VASc score of 1 (men) or 2 (women). In Asian AF patients, the risk of stroke substantially increased after the age of 50 years [71], and in a recent nationwide cohort study of non-anticoagulated Taiwanese AF patients with a single stroke risk factor in addition to sex, even an age of 20-49 years was associated with an annual rate of stroke of $1.33 \%$ [72] (which is above the tipping point for NOACs use).

Overall, despite some heterogeneity in the statistical significance of the relationships of various stroke risk factors with observed stroke rates, the presence of a single $\mathrm{CHA}_{2} \mathrm{DS}_{2}$-VASc stroke risk factor was associated with increased 


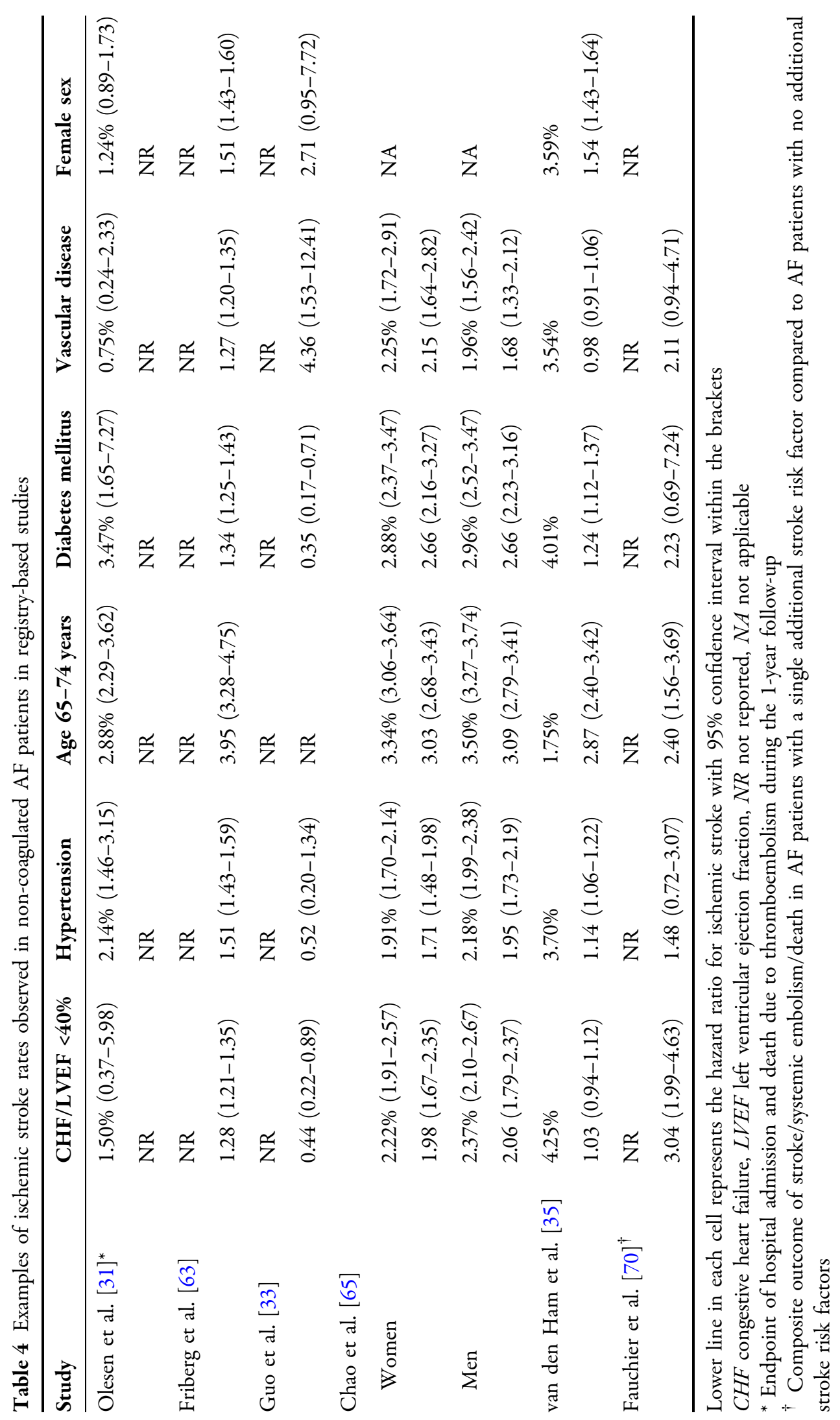


risk of ischemic stroke or a composite outcome of stroke/systemic embolism/death in observational AF cohort studies (Table 4). Notwithstanding the discrepancies in methodology, coagulation status, and the characteristics of various AF populations, the annual rates of stroke in AF patients with a single additional stroke risk factor were around or well above the contemporary threshold for the initiation of OAC therapy, either with well-controlled VKAs or, preferably, with NOACs. Improvements in the management of OAC therapy and better safety profile of available OAC treatments coupled with the data from contemporary AF cohorts facilitate the use of OAC in this subset of AF patients.

\section{EFFECTIVENESS OF OAC IN AF PATIENTS WITH A SINGLE ADDITIONAL STROKE RISK FACTOR IN "REAL-WORLD" \\ OBSERVATIONAL STUDIES}

In the aforementioned Danish nationwide $\mathrm{AF}$ cohort study, the use of warfarin in AF patients with a single additional stroke risk factor reduced their stroke risk to the level comparable to AF patients with no additional stroke risk factors (HR 1.33; 95\% CI 0.76-2.33) [57]. Also, the use of warfarin in AF patients with a single additional stroke risk factor was associated with reduction in stroke compared to aspirin (HR 0.67; 95\% CI 0.43-1.06) or no therapy (HR 0.69; 95\% CI 0.48-0.99), and there was no increase in the bleeding rates with warfarin relative to aspirin (HR 1.06; 95\% CI 0.78-1.43). The use of OAC was also associated with significant reduction in mortality in comparison to the use of aspirin (HR $0.68 ; \quad 95 \%$ CI $0.55-0.83$ ) or no antithrombotic therapy (HR $0.42 ; 95 \%$ CI 0.36-0.50) in these patients [57].
In a recent hospital registry-based study in France, the use of OAC among AF patients with no additional stroke risk factors was associated with non-significant reduction in a composite outcome of stroke, systemic embolism, or death compared to no OAC therapy (HR 0.68; 95\% CI $0.35-1.31, p=0.25)$. However, the use of OAC in AF patients with a single additional stroke risk factor was clearly associated with significant advantage in terms of reduction in stroke, systemic embolism, or death compared with no OAC therapy (HR 0.59; 95\% CI 0.40-0.86, $p=0.007$ ) [70].

The evaluation of ultimate benefit of OAC therapy in AF patients requires consideration of both efficacy and safety of oral anticoagulant drugs, since these drugs inevitably exert an impact on hemostasis, thus increasing the risk of bleeding events. The concept of net clinical benefit (NCB) from OAC therapy represents a balance of the prevention of AF-related thromboembolic events against the risk of bleeding with OAC, whereby the most serious bleeding events (essentially ICH) have a greater weight than ischemic strokes because of worse outcome in terms of higher fatality or extensive permanent disability associated with the former. The first quantitative assessment of such weighted NCB with warfarin treatment in AF patients used the following formula: the annual rate of ischemic stroke or systemic embolism prevented by warfarin minus the rate of OAC-related $\mathrm{ICH}$ multiplied by a factor of 1.5, which was chosen arbitrarily [73]. A similar concept and other approaches have been subsequently used to estimate the NCB of NOACs or VKAs or other antithrombotic therapies in patients with AF [74-78].

An NCB analysis among AF patients with a $\mathrm{CHA}_{2} \mathrm{DS}_{2}$-VASc score of $\geq 1$ in the Danish nationwide AF cohort yielded a neutral or positive net clinical benefit with VKA therapy 
(the NCB with warfarin in patients with a $\mathrm{CHA}_{2} \mathrm{DS}_{2}$-VASc score of 1 was neutral: 0.25 [95\% CI -0.86 to 1.36]) [55] and a positive net clinical benefit with NOACs (in patients with a $\mathrm{CHA}_{2} \mathrm{DS}_{2}$-VASc score of 1 the $\mathrm{NCB}$ with dabigatran $150 \mathrm{mg}$ twice daily, for example, was 1.36 [95\% CI 0.86-2.58]) [54].

In the study of a community-based cohort of unselected AF patients with one non-gender-related additional stroke risk factor [70], Fauchier et al. reported that the use of VKA was associated with positive NCB in comparison to no therapy (NCB 0.30; 95\% CI 0.15-0.61, or 1.42 ; 95\% CI 1.01-1.99, using the NCB calculation method proposed by Singer et al. [73] or Connolly et al. [79], respectively), or aspirin (NCB 0.43 ; 95\% CI $0.24-0.78$, or 2.14 ; 95\% CI 1.62-2.82), whilst the use of aspirin yielded a negative NCB when compared to no therapy (NCB $-0.13 ; 95 \% \mathrm{CI}-1.06$ to -0.02 , or $-0.72 ; 95 \%$ CI -1.50 to -0.34$)$ [70]. The Swedish AF cohort study also showed that the use of OAC (VKAs) was associated with a positive $\mathrm{NCB}$ in almost all $\mathrm{AF}$ patients, excluding only those with a $\mathrm{CHA}_{2} \mathrm{DS}_{2}$-VASc score of 0 at moderately increased risk of bleeding; of note, in AF patients with a $\mathrm{CHA}_{2} \mathrm{DS}_{2}$-VASc score of 1 , the NCB was 0.30 ; 95\% CI 0.10-0.40 [56].

Although VKA therapy is generally very well managed in Sweden in comparison to many other countries [80], the treatment effect of NOACs compared with VKA for the prevention of stroke and systemic embolism seems consistent regardless of cTTR [81], related to the observation that there is no significant change in rate of major bleedings across center average TTR and individual TTR quartiles $[82,83]$. Moreover, well-managed VKA therapy with a TTR of $\geq 70 \%$ is often difficult to maintain in clinical practice, as shown in many registry-based studies $[84,85]$ or even in randomized clinical trials [86]. Even though the median TTR was $73 \%$, a TTR of $\geq 70 \%$ was achieved in only $55 \%$ of the patients [87]. Thus, NOACs may be preferred over VKAs in many clinical circumstances, provided that a good adherence to therapy can be accomplished. An increasing body of evidence suggests that the performance of NOACs in real-world settings is broadly similar to their efficacy and safety in the respective randomized clinical trial [88-106].

The outcomes of VKA therapy are highly dependent on the quality of anticoagulation, as measured by individual patient's TTR [84], and OAC-naive patients are particularly vulnerable to OAC-related serious adverse events (both thromboembolism and bleeding) in the first months of treatment, during the OAC inception

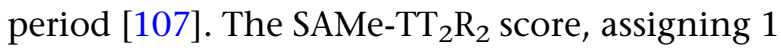
point each to female sex, age of $<60$ years, history of two or more comorbidities (i.e., hypertension, diabetes mellitus, coronary artery disease/myocardial infarction, peripheral arterial disease, congestive heart failure, previous stroke, pulmonary disease, and hepatic or renal disease) and treatment with drugs interacting with VKAs (e.g., amiodarone) and 2 points each for current or recent tobacco use and non-Caucasian ethnicity, has been shown to have reasonably good predictive ability to identify OAC-naive AF patients who would do well on VKAs (patients with a SAMe-TT ${ }_{2} \mathrm{R}_{2}$ score of $0-2$ ), whilst those with a SAMe- $\mathrm{TT}_{2} \mathrm{R}_{2}$ score of $>2$ should be prescribed a NOAC [108]. The SAMe-TT ${ }_{2} \mathrm{R}_{2}$ score has been shown to be predictive not only of the quality of anticoagulation with VKAs but also of all-cause mortality and composite endpoint of thromboembolic events, major bleeding, and mortality [109-114].

Given the superior safety of NOACs relative to VKAs in terms of reduced risk of ICH and the advantage of more convenient use in 
comparison to VKAs, NOACs should be considered as the first-line antithrombotic treatment option in most patients with $\mathrm{AF}$ and a single additional stroke risk factor. Alternatively, particularly in case of a restricted reimbursement policy, the choice between NOACs and VKAs could be guided by the $\mathrm{SAMe}-\mathrm{TT}_{2} \mathrm{R}_{2}$ score. Thus, patients with a SAMe- $\mathrm{TT}_{2} \mathrm{R}_{2}$ score of $0-2$ would potentially do well on VKAs, whilst those with a SAMe-TT ${ }_{2} \mathrm{R}_{2}$ score of $>2$ are less likely to do well on VKA, unless additional measures such as more regular/frequent follow-up, INR checks and counselling should be given, or these days, a NOAC.

\section{PATIENT VALUES AND PREFERENCES}

Although OAC therapy achieves the greatest absolute reduction of stroke risk in AF patients at highest risk of stroke, AF patients at "low to moderate" risk of stroke still have a clear positive net clinical benefit from OAC therapy (particularly with NOACs). Nevertheless, in a recent Canadian combined survey on physicians and AF patients [115] the fear of OAC-related major bleeding complications has been ranked as the highest-priority OAC therapy-related consideration by physicians, whilst it was placed at only 5th position by patients (of note, patients were more concerned with interactions of OAC with food and drugs, possibility of rapid reversal of OAC effect in emergency situations, the clinical experience with particular $\mathrm{OAC}$, or the requirement for regular blood testing). Another study using an iPad-facilitated questionnaire revealed that $\mathrm{AF}$ patients were willing to suffer four major bleeding events in exchange for preventing just one stroke and, in their view, the treatment threshold for the acceptance of OAC therapy was a minimum absolute stroke risk reduction of $0.8 \%$ per year (a number needed to treat 125 AF patients) [116].

Moreover, all health-related quality of life (QoL) scores (SF36) in a recent study were found to be significantly lower in warfarin-treated versus the NOAC-treated patients, which may be explained by the higher bleeding rates and hospital admissions while on warfarin treatment [117].

Recent survey among European electrophysiology centers showed that practicing European cardiologists were spending a considerable amount of time discussing individual risk profiles and available therapies with their AF patients [118]. In a randomized trial, educational interventions in AF patients resulted in improved quality of oral anticoagulation with VKAs [119]. Engaging AF patients in the informed shared decision-making about OAC therapy (either VKAs or NOACs) facilitates their understanding of treatment and helps in eliciting (and correcting) their possible misperceptions or personal barriers to OAC treatment, thus improving their adherence to therapy and ultimate treatment effects $[120,121]$. A questionnaire-based tool facilitating the identification of patients' values and preferences and supporting the decision regarding the use of VKAs or NOACs has been described [122].

Importantly, the individual risk profile of $\mathrm{AF}$ patients initially presenting as a "borderline" or "moderate" risk category may change over time [123]. Regular clinical follow-up of these patients and periodical re-assessment of individual patient risk profile are mandated, since aging and/or development of cardiac, renal, or other comorbidities may aggravate the patient's stroke or bleeding risk [124], which could sometimes require adjustments in OAC treatment with respect to the choice of oral 
anticoagulant drug and appropriate dosing [125].

\section{CONCLUSION}

Patients with non-valvular AF and a single additional stroke risk factor may be denied OAC because of the misperception that their risk of stroke is not sufficiently high to justify the use of OAC (either VKAs or NOACs). Observational data from real-world AF cohorts show that the annual stroke rates in such patients are higher than in patients with no additional stroke risk factors and are around or well above the contemporary threshold for OAC treatment. Well-controlled VKA or NOACs therapy in these patients has been associated with a positive net clinical benefit owing to reduction in the risk of stroke, systemic embolism, or death in comparison to no therapy or aspirin, with no increase in the risk of bleeding relative to aspirin.

Given the superior safety and convenience of NOACs relative to VKAs, NOACs should be considered as the first-line antithrombotic treatment option in most AF patients with a single additional stroke risk factor. Regular clinical follow-up and periodical re-assessment of individual patient risk profile are mandated, since aging and/or development of cardiac, renal, or other comorbidities may aggravate the patient's stroke or bleeding risk.

\section{ACKNOWLEDGEMENTS}

No funding or sponsorship was received for this study or publication of this article. All named authors meet the International Committee of Medical Journal Editors (ICMJE) criteria for authorship for this manuscript, take responsibility for the integrity of the work as a whole, and have given final approval for the version to be published.

Disclosures. Potpara TS received speaker fees from Bayer and Pfizer, Mujovic $\mathrm{N}$ received speaker fees from Boehringer Ingelheim, Nedeljkovic $M$ received speaker fees from Bayer, Fauchier L has served as a consultant for Bayer, BMS/Pfizer, Boehringer Ingelheim, and Daiichi Sankyo, and he has been on the speakers bureau from Bayer, BMS/Pfizer, and Boehringher Ingelheim, Lip GYH has served as a consultant for Bayer/Janssen, Astellas, Merck, Sanofi, BMS/Pfizer, Biotronik, Medtronic, Portola, Boehringer Ingelheim, Microlife, and Daiichi-Sankyo and as a speaker for Bayer, BMS/ Pfizer, Medtronic, Boehringer Ingelheim, Microlife, Roche, and Daiichi-Sankyo. Dagres N, Vasic D, Asanin M, Narin F, and Blomstrom-Lundqvist $\mathrm{C}$ have no disclosures pertinent to this work.

Compliance with Ethics Guidelines. This article is based on previously conducted studies and does not involve any new studies of human or animal subjects performed by any of the authors.

Data Availability. Data sharing is not applicable to this article as no datasets were generated or analyzed during the current study.

Open Access. This article is distributed under the terms of the Creative Commons Attribution-NonCommercial 4.0 International License (http://creativecommons.org/licenses/ by-nc/4.0/), which permits any noncommercial use, distribution, and reproduction in any medium, provided you give appropriate credit to the original author(s) and the source, provide a link to the Creative Commons license, and indicate if changes were made. 


\section{REFERENCES}

1. Chugh SS, Havmoeller R, Narayanan K, et al. Worldwide epidemiology of atrial fibrillation: a Global Burden of Disease 2010 Study. Circulation. 2014;129:837-47.

2. Potpara TS, Lane DA. Diving to the foot of an iceberg: the SEARCH for undiagnosed atrial fibrillation. Thromb Haemost. 2014;112:1-3.

3. Lip GY, Fauchier L, Freedman SB, et al. Atrial fibrillation. Nat Rev Dis Primers. 2016;2:16016.

4. Friberg L, Rosenqvist M, Lindgren A, Terent A, Norrving B, Asplund K. High prevalence of atrial fibrillation among patients with ischemic stroke. Stroke. 2014;45:2599-605.

5. Freedman B, Potpara TS, Lip GY. Stroke prevention in atrial fibrillation. Lancet. 2016;388:806-17.

6. Steger C, Pratter A, Martinek-Bregel M, Avanzini M, Valentin A, Slany J, Stollberger C. Stroke patients with atrial fibrillation have a worse prognosis than patients without: data from the Austrian stroke registry. Eur Heart J. 2004;25:1734-40.

7. Hart RG, Pearce LA, Aguilar MI. Meta-analysis: antithrombotic therapy to prevent stroke in patients who have nonvalvular atrial fibrillation. Ann Intern Med. 2007;146:857-67.

8. Connolly SJ, Eikelboom J, Joyner C, et al. Apixaban in patients with atrial fibrillation. New Engl J Med. 2011;364:806-17.

9. Patel MR, Mahaffey KW, Garg J, et al. Rivaroxaban versus warfarin in nonvalvular atrial fibrillation. New Engl J Med. 2011;365:883-91.

10. Connolly SJ, Ezekowitz MD, Yusuf S, et al. Dabigatran versus warfarin in patients with atrial fibrillation. New Engl J Med. 2009;361:1139-51.

11. Giugliano RP, Ruff CT, Braunwald E, et al. Edoxaban versus warfarin in patients with atrial fibrillation. New Engl J Med. 2013;369:2093-104.

12. Ruff CT, Giugliano RP, Braunwald E, et al. Comparison of the efficacy and safety of new oral anticoagulants with warfarin in patients with atrial fibrillation: a meta-analysis of randomised trials. Lancet. 2014;383:955-62.

13. Eckman MH, Singer DE, Rosand J, Greenberg SM. Moving the tipping point: the decision to anticoagulate patients with atrial fibrillation. Circ Cardiovasc Qual Outcomes. 2011;4:14-21.
14. Lip GY, Laroche C, Dan GA, et al. 'Real-world' antithrombotic treatment in atrial fibrillation: the EORP-AF pilot survey. Am J Med. 2014;127:519-29 (e1).

15. Hsu JC, Maddox TM, Kennedy KF, et al. Oral anticoagulant therapy prescription in patients with atrial fibrillation across the spectrum of stroke risk: insights from the NCDR PINNACLE registry. JAMA Cardiol. 2016;1:55-62.

16. Lip GY, Al-Khatib SM, Cosio FG, et al. Contemporary management of atrial fibrillation: what can clinical registries tell us about stroke prevention and current therapeutic approaches? J Am Heart Assoc. 2014. doi:10.1161/JAHA.114. 001179.

17. Potpara TS, Dan GA, Trendafilova E, et al. Stroke prevention in atrial fibrillation and 'real world' adherence to guidelines in the Balkan region: the BALKAN-AF survey. Sci Rep. 2016;6:20432.

18. Kakkar AK, Mueller I, Bassand JP, et al. Risk profiles and antithrombotic treatment of patients newly diagnosed with atrial fibrillation at risk of stroke: perspectives from the international, observational, prospective GARFIELD registry. PLoS One. 2013;8:e63479.

19. Ogawa Satoshi AK, Tse H-F, et al. The APHRS's statement on antithrombotic therapy of patients with nonvalvular atrial fibrillation. J Arrhythm. 2013;29:190-200.

20. January CT, Wann LS, Alpert JS, et al. 2014 AHA/ ACC/HRS guideline for the management of patients with atrial fibrillation: executive summary: a report of the American College of Cardiology/American Heart Association Task Force on practice guidelines and the Heart Rhythm Society. Circulation. 2014;130:2071-104.

21. Senoo K, Lau YC, Lip GY. Updated NICE guideline: management of atrial fibrillation (2014). Expert Rev Cardiovasc Ther. 2014;12:1037-40.

22. JCS Joint Working Group. Guidelines for pharmacotherapy of atrial fibrillation (JCS 2013). Circ J. 2014;78:1997-2021.

23. Verma A, Cairns JA, Mitchell LB, et al. Focused update of the Canadian Cardiovascular Society guidelines for the management of atrial fibrillation. Can J Cardiol. 2014;2014(30):1114-30.

24. Kirchhof P, Benussi S, Kotecha D, et al. 2016 ESC Guidelines for the management of atrial fibrillation developed in collaboration with EACTS. Euro Heart J. 2016. doi:10.1093/eurheartj/ehw210. 
25. Camm AJ, Lip GY, De Caterina R, et al. 2012 focused update of the ESC guidelines for the management of atrial fibrillation: an update of the 2010 ESC guidelines for the management of atrial fibrillation. Developed with the special contribution of the European Heart Rhythm Association. Euro Heart J. 2012;33:2719-47.

26. Hughes M, Lip GY, Guideline Development Group, National Clinical Guideline for Management of Atrial Fibrillation in Primary and Secondary Care, National Institute for Health and Clinical Excellence. Stroke and thromboembolism in atrial fibrillation: a systematic review of stroke risk factors, risk stratification schema and cost effectiveness data. Thromb Haemost. 2008;99:295-304.

27. Lip GY, Nieuwlaat R, Pisters R, Lane DA, Crijns HJ. Refining clinical risk stratification for predicting stroke and thromboembolism in atrial fibrillation using a novel risk factor-based approach: the euro heart survey on atrial fibrillation. Chest. 2010;137:263-72.

28. Olesen JB, Torp-Pedersen C, Hansen ML, Lip GY. The value of the CHA2DS2-VASc score for refining stroke risk stratification in patients with atrial fibrillation with a CHADS2 score 0-1: a nationwide cohort study. Thromb Haemost. 2012;107:1172-9.

29. Chen JY, Zhang AD, Lu HY, Guo J, Wang FF, Li ZC. CHADS2 versus CHA2DS2-VASc score in assessing the stroke and thromboembolism risk stratification in patients with atrial fibrillation: a systematic review and meta-analysis. J Geriatr Cardiol. 2013;10:258-66.

30. Olesen JB, Torp-Pedersen C. Stroke risk in atrial fibrillation: do we anticoagulate CHADS2 or CHA2DS2-VASc $>/=1$, or higher? Thromb Haemost. 2015;113:1165-9.

31. Olesen JB, Lip GY, Hansen ML, et al. Validation of risk stratification schemes for predicting stroke and thromboembolism in patients with atrial fibrillation: nationwide cohort study. BMJ. 2011;342:d124.

32. Potpara TS, Polovina MM, Licina MM, Marinkovic JM, Prostran MS, Lip GY. Reliable identification of "truly low" thromboembolic risk in patients initially diagnosed with "lone" atrial fibrillation: the Belgrade atrial fibrillation study. Circ Arrhythm Electrophysiol. 2012;5:319-26.

33. Guo Y, Apostolakis S, Blann AD, et al. Validation of contemporary stroke and bleeding risk stratification scores in non-anticoagulated Chinese patients with atrial fibrillation. Int J Cardiol. 2013;168:904-9.
34. Chao TF, Lin YJ, Tsao HM, et al. CHADS(2) and $\mathrm{CHA}(2) \mathrm{DS}(2)-\mathrm{VASc}$ scores in the prediction of clinical outcomes in patients with atrial fibrillation after catheter ablation. J Am Coll Cardiol. 2011;58:2380-5.

35. van den Ham HA, Klungel OH, Singer DE, Leufkens HG, van Staa TP. Comparative performance of ATRIA, CHADS2, and CHA2DS2-VASc risk scores predicting stroke in patients with atrial fibrillation: results from a national primary care database. J Am Coll Cardiol. 2015;66:1851-9.

36. Lip GY. Stroke and bleeding risk assessment in atrial fibrillation: when, how, and why? Eur Heart J. 2013;34:1041-9.

37. Chao TF, Liu CJ, Wang KL, et al. Using the CHA2DS2-VASc score for refining stroke risk stratification in 'low-risk' Asian patients with atrial fibrillation. J Am Coll Cardiol. 2014;64:1658-65.

38. Potpara TS, Olesen JB. Comparing the ATRIA, CHADS2, and CHA2DS2-VASc scores for stroke prediction in atrial fibrillation. J Am Coll Cardiol. 2016;67:2316-7.

39. Lip GY, Skjoth F, Nielsen PB, Larsen TB. Non-valvular atrial fibrillation patients with none or one additional risk factor of the CHA2DS2-VASc score. A comprehensive net clinical benefit analysis for warfarin, aspirin, or no therapy. Thromb Haemost. 2015;114:826-34.

40. Lip GY, Nielsen PB, Skjoth F, Lane DA, Rasmussen LH, Larsen TB. The value of the European Society of Cardiology guidelines for refining stroke risk stratification in patients with atrial fibrillation categorized as low risk using the anticoagulation and risk factors in atrial fibrillation stroke score: a nationwide cohort study. Chest. 2014;146:1337-46.

41. Aspberg S, Chang Y, Atterman A, Bottai M, Go AS, Singer DE. Comparison of the ATRIA, CHADS2, and CHA2DS2-VASc stroke risk scores in predicting ischaemic stroke in a large Swedish cohort of patients with atrial fibrillation. Eur Heart J. 2016;37:3203-10.

42. Hijazi Z, Oldgren J, Siegbahn A, Granger CB, Wallentin L. Biomarkers in atrial fibrillation: a clinical review. Eur Heart J. 2013;34:1475-80.

43. Hijazi Z, Lindback J, Alexander JH, et al. The ABC (age, biomarkers, clinical history) stroke risk score: a biomarker-based risk score for predicting stroke in atrial fibrillation. Eur Heart J. 2016;37:1582-90.

44. Donal E, Lip GY, Galderisi M, et al. EACVI/EHRA expert consensus document on the role of multi-modality imaging for the evaluation of 
patients with atrial fibrillation. Eur Heart J Cardiovasc Imaging. 2016;17:355-83.

45. Oldgren J, Hijazi Z, Lindback J, et al. Performance and validation of a novel biomarker-based stroke risk score for atrial fibrillation. Circulation. 2016. doi:10.1161/CIRCULATIONAHA.116.022802

46. Emdin CA, Wong CX, Hsiao AJ, et al. Atrial fibrillation as risk factor for cardiovascular disease and death in women compared with men: systematic review and meta-analysis of cohort studies. BMJ. 2016;532:h7013.

47. Overvad TF, Rasmussen LH, Skjoth F, et al. Female sex as a risk factor for thromboembolism and death in patients with incident atrial fibrillation. The prospective Danish Diet, Cancer and Health study. Thromb Haemost. 2014;112:789-95.

48. Friberg L, Benson L, Rosenqvist M, Lip GY. Assessment of female sex as a risk factor in atrial fibrillation in Sweden: nationwide retrospective cohort study. BMJ. 2012;344:e3522.

49. Mikkelsen AP, Lindhardsen J, Lip GY, Gislason GH, Torp-Pedersen C, Olesen JB. Female sex as a risk factor for stroke in atrial fibrillation: a nationwide cohort study. J Thromb Haemost. 2012;10:1745-51.

50. Avgil Tsadok M, Jackevicius CA, Rahme $E$, Humphries KH, Behlouli H, Pilote L. Sex differences in stroke risk among older patients with recently diagnosed atrial fibrillation. JAMA. 2012;307:1952-8.

51. Potpara TS, Marinkovic JM, Polovina MM, et al. Gender-related differences in presentation, treatment and long-term outcome in patients with first-diagnosed atrial fibrillation and structurally normal heart: the Belgrade atrial fibrillation study. Int J Cardiol. 2012;161:39-44.

52. Cove CL, Albert CM, Andreotti F, Badimon L, Van Gelder IC, Hylek EM. Female sex as an independent risk factor for stroke in atrial fibrillation: possible mechanisms. Thromb Haemost. 2014;111:385-91.

53. Joundi RA, Cipriano LE, Sposato LA, Saposnik G, Stroke Outcomes Research Working Group. Ischemic stroke risk in patients with atrial fibrillation and CHA2DS2-VASc score of 1: systematic review and meta-analysis. Stroke J Cereb Circu. 2016;47:1364-7.

54. Banerjee A, Lane DA, Torp-Pedersen C, Lip GY. Net clinical benefit of new oral anticoagulants (dabigatran, rivaroxaban, apixaban) versus no treatment in a 'real world' atrial fibrillation population: a modelling analysis based on a nationwide cohort study. Thromb Haemost. 2012;107:584-9.
55. Olesen JB, Lip GYH, Lindhardsen J, et al. Risks of thromboembolism and bleeding with thromboprophylaxis in patients with atrial fibrillation: a net clinical benefit analysis using a 'real world' nationwide cohort study. Thromb Haemost. 2011;106:739-49.

56. Friberg L, Rosenqvist M, Lip GY. Net clinical benefit of warfarin in patients with atrial fibrillation: a report from the Swedish atrial fibrillation cohort study. Circulation. 2012;125:2298-307.

57. Lip GY, Skjoth F, Rasmussen LH, Larsen TB. Oral anticoagulation, aspirin, or no therapy in patients with nonvalvular AF with 0 or 1 stroke risk factor based on the CHA2DS2-VASc score. J Am Coll Cardiol. 2015;65:1385-94.

58. Huang D, Anguo L, Yue WS, Yin L, Tse HF, Siu CW. Refinement of ischemic stroke risk in patients with atrial fibrillation and CHA2 DS2 -VASc score of 1 . Pacing Clin Electrophysiol. 2014;37:1442-7.

59. Komatsu T, Tachibana H, Satoh $\mathrm{Y}$, et al. Relationship between CHA(2)DS(2)-VASc scores and ischemic stroke/cardiovascular events in Japanese patients with paroxysmal atrial fibrillation not receiving anticoagulant therapy. J Cardiol. 2012;59:321-8.

60. Larsen TB, Lip GY, Skjoth F, Due KM, Overvad K, Hvilsted Rasmussen L. Added predictive ability of the CHA2DS2VASc risk score for stroke and death in patients with atrial fibrillation: the prospective Danish Diet, Cancer, and Health cohort study. Circu Cardiovasc Qual Outcomes. 2012;5:335-42.

61. Suzuki S, Yamashita T, Okumura K, et al. Incidence of ischemic stroke in Japanese patients with atrial fibrillation not receiving anticoagulation therapy-pooled analysis of the Shinken Database, J-RHYTHM Registry, and Fushimi AF Registry. Circ J. 2015;79:432-8.

62. Olesen JB, Sorensen $\mathrm{R}$, Hansen $\mathrm{ML}$, et al. Non-vitamin $\mathrm{K}$ antagonist oral anticoagulation agents in anticoagulant naive atrial fibrillation patients: Danish nationwide descriptive data 2011-2013. Europace. 2015;17:187-93.

63. Friberg L, Rosenqvist M, Lip GY. Evaluation of risk stratification schemes for ischaemic stroke and bleeding in 182678 patients with atrial fibrillation: the Swedish atrial fibrillation cohort study. Eur Heart J. 2012;33:1500-10.

64. Forslund T, Wettermark B, Wandell P, von Euler M, Hasselstrom J, Hjemdahl P. Risks for stroke and bleeding with warfarin or aspirin treatment in patients with atrial fibrillation at different CHA(2)DS(2)VASc scores: experience from the 
Stockholm region. Eur J Clin Pharmacol. 2014;70:1477-85.

65. Chao TF, Liu CJ, Wang KL, et al. Should atrial fibrillation patients with 1 additional risk factor of the CHA2DS2-VASc score (beyond sex) receive oral anticoagulation? J Am Coll Cardiol. 2015;65:635-42.

66. Friberg L, Skeppholm M, Terent A. Benefit of anticoagulation unlikely in patients with atrial fibrillation and a CHA2DS2-VASc score of 1 . J Am Coll Cardiol. 2015;65:225-32.

67. Allan V, Banerjee A, Shah AD, et al. Net clinical benefit of warfarin in individuals with atrial fibrillation across stroke risk and across primary and secondary care. Heart. 2016. doi:10.1136/ heartjnl-2016-309910.

68. Nielsen PB, Chao TF. The risks of risk scores for stroke risk assessment in atrial fibrillation. Thromb Haemost. 2015;113:1170-3.

69. Nielsen PB, Larsen TB, Skjoth F, Overvad TF, Lip GY. Stroke and thromboembolic event rates in atrial fibrillation according to different guideline treatment thresholds: a nationwide cohort study. Sci Rep. 2016;6:27410.

70. Fauchier L, Lecoq C, Clementy $\mathrm{N}$, et al. Oral anticoagulation and the risk of stroke or death in patients with atrial fibrillation and one additional stroke risk factor: the Loire Valley atrial fibrillation project. Chest. 2016;149:960-8.

71. Chao TF, Wang KL, Liu CJ, et al. Age threshold for increased stroke risk among patients with atrial fibrillation: a nationwide cohort study from Taiwan. J Am Coll Cardiol. 2015;66:1339-47.

72. Hung Y, Chao TF, Liu CJ, et al. Is an oral anticoagulant necessary for young atrial fibrillation patients with a CHA2DS2-VASc score of 1 (men) or 2 (women)? J Am Heart Assoc. 2016;5:e003839.

73. Singer DE, Chang Y, Fang MC, et al. The net clinical benefit of warfarin anticoagulation in atrial fibrillation. Ann Intern Med. 2009;151:297-305.

74. Eikelboom JW, Connolly SJ, Hart RG, et al. Balancing the benefits and risks of 2 doses of dabigatran compared with warfarin in atrial fibrillation. J Am Coll Cardiol. 2013;62:900-8.

75. Renda G, di Nicola M, De Caterina R. Net clinical benefit of non-vitamin $\mathrm{K}$ antagonist oral anticoagulants versus warfarin in phase III atrial fibrillation trials. Am J Med. 2015;128:1007-14 (e2).
76. Rasmussen LH, Larsen TB, Graungaard T, Skjoth F, Lip GY. Primary and secondary prevention with new oral anticoagulant drugs for stroke prevention in atrial fibrillation: indirect comparison analysis. BMJ. 2012;345:e7097.

77. Lip GY, Larsen TB, Skjoth F, Rasmussen LH. Indirect comparisons of new oral anticoagulant drugs for efficacy and safety when used for stroke prevention in atrial fibrillation. J Am Coll Cardiol. 2012;60:738-46.

78. Hsu JC, Hsieh CY, Yang YH, Lu CY. Net clinical benefit of oral anticoagulants: a multiple criteria decision analysis. PLoS One. 2015;10:e0124806.

79. Connolly SJ, Eikelboom JW, Ng J, et al. Net clinical benefit of adding clopidogrel to aspirin therapy in patients with atrial fibrillation for whom vitamin $\mathrm{K}$ antagonists are unsuitable. Ann Intern Med. 2011;155:579-86.

80. Wieloch M, Sjalander A, Frykman V, Rosenqvist M, Eriksson N, Svensson PJ. Anticoagulation control in Sweden: reports of time in therapeutic range, major bleeding, and thrombo-embolic complications from the national quality registry AuriculA. Eur Heart J. 2011;32:2282-9.

81. Piccini JP, Hellkamp AS, Lokhnygina Y, et al. Relationship between time in therapeutic range and comparative treatment effect of rivaroxaban and warfarin: results from the ROCKET AF trial. J Am Heart Assoc. 2014;3:e000521.

82. Amin A, Deitelzweig S, Jing Y, et al. Estimation of the impact of warfarin's time-in-therapeutic range on stroke and major bleeding rates and its influence on the medical cost avoidance associated with novel oral anticoagulant use-learnings from ARISTOTLE, ROCKET-AF, and RE-LY trials. J Thromb Thrombolysis. 2014;38:150-9.

83. Wallentin L, Yusuf S, Ezekowitz MD, et al. Efficacy and safety of dabigatran compared with warfarin at different levels of international normalised ratio control for stroke prevention in atrial fibrillation: an analysis of the RE-LY trial. Lancet. 2010;376:975-83.

84. Mearns ES, White CM, Kohn CG, et al. Quality of vitamin $\mathrm{K}$ antagonist control and outcomes in atrial fibrillation patients: a meta-analysis and meta-regression. Thromb J. 2014;12:14.

85. Pokorney SD, Simon DN, Thomas L, et al. Patients' time in therapeutic range on warfarin among US patients with atrial fibrillation: results from ORBIT-AF registry. Am Heart J. 2015;170:141-8 (148 e1). 
86. Agarwal S, Hachamovitch R, Menon V. Current trial-associated outcomes with warfarin in prevention of stroke in patients with nonvalvular atrial fibrillation: a meta-analysis. Arch Intern Med. 2012;172:623-31 (discussion 631-3).

87. Patel AD, Tan $\mathrm{MK}$, Angaran $\mathrm{P}$, et al. Risk stratification and stroke prevention therapy care gaps in Canadian atrial fibrillation patients (from the Co-ordinated National Network to Engage Physicians in the Care and Treatment of Patients With Atrial Fibrillation chart audit). Am J Cardiol. 2015;115:641-6.

88. Vaughan Sarrazin MS, Jones M, Mazur A, Chrischilles E, Cram P. Bleeding rates in Veterans Affairs patients with atrial fibrillation who switch from warfarin to dabigatran. Am J Med. 2014;127:1179-85.

89. Larsen TB, Gorst-Rasmussen A, Rasmussen LH, Skjoth F, Rosenzweig M, Lip GY. Bleeding events among new starters and switchers to dabigatran compared with warfarin in atrial fibrillation. Am J Med. 2014;127:650-656 (e5).

90. Graham DJ, Reichman ME, Wernecke M, et al. Cardiovascular, bleeding, and mortality risks in elderly Medicare patients treated with dabigatran or warfarin for nonvalvular atrial fibrillation. Circulation. 2015;131:157-64.

91. Hernandez I, Baik SH, Pinera A, Zhang Y. Risk of bleeding with dabigatran in atrial fibrillation. JAMA Intern Med. 2015;175:18-24.

92. Lauffenburger JC, Farley JF, Gehi AK, Rhoney DH, Brookhart MA, Fang G. Effectiveness and safety of dabigatran and warfarin in real-world US patients with non-valvular atrial fibrillation: a retrospective cohort study. J Am Heart Assoc. 2015. doi:10.1161/ JAHA.115.001798.

93. Abraham NS, Singh S, Alexander GC, et al. Comparative risk of gastrointestinal bleeding with dabigatran, rivaroxaban, and warfarin: population based cohort study. BMJ. 2015;350:h1857.

94. Avgil-Tsadok M, Jackevicius CA, Essebag V, et al. Dabigatran use in elderly patients with atrial fibrillation. Thromb Haemost. 2016;115: $152-60$.

95. Seeger JD, Bykov K, Bartels DB, Huybrechts K, Zint K, Schneeweiss S. Safety and effectiveness of dabigatran and warfarin in routine care of patients with atrial fibrillation. Thromb Haemost. 2015; 114:1277-89.

96. Villines TC, Schnee J, Fraeman K, et al. A comparison of the safety and effectiveness of dabigatran and warfarin in non-valvular atrial fibrillation patients in a large healthcare system. Thromb Haemost. 2015;114:1290-8.

97. Potpara TS. Dabigatran in 'real-world' clinical practice for stroke prevention in patients with non-valvular atrial fibrillation. Thromb Haemost. 2015;114:1093-8.

98. Camm AJ, Amarenco P, Haas S, et al. XANTUS: a real-world, prospective, observational study of patients treated with rivaroxaban for stroke prevention in atrial fibrillation. Eur Heart J. 2016;37:1145-53.

99. Coleman CI, Antz M, Ehlken B, Evers T. REal-LIfe Evidence of stroke prevention in patients with atrial Fibrillation - the RELIEF study. Int $\mathrm{J}$ Cardiol. 2016;203:882-4

100. Tamayo S, Frank Peacock W, Patel M, et al. Characterizing major bleeding in patients with nonvalvular atrial fibrillation: a pharmacovigilance study of 27467 patients taking rivaroxaban. Clin Cardiol. 2015;38:63-8.

101. Staerk L, Fosbol EL, Lip GY, et al. Ischaemic and haemorrhagic stroke associated with non-vitamin $\mathrm{K}$ antagonist oral anticoagulants and warfarin use in patients with atrial fibrillation: a nationwide cohort study. Euro Heart J. 2016. doi:10.1093/eurheartj/ ehw496.

102. Freedman B, Lip GY. "Unreal world" or "real world" data in oral anticoagulant treatment of atrial fibrillation. Thromb Haemost. 2016;116:587-9.

103. Carmo J, Moscoso Costa F, Ferreira J, Mendes M. Dabigatran in real-world atrial fibrillation. Meta-analysis of observational comparison studies with vitamin $\mathrm{K}$ antagonists. Thromb Haemost. 2016;116:754-63.

104. Yao X, Abraham NS, Sangaralingham LR, et al. Effectiveness and safety of dabigatran, rivaroxaban, and apixaban versus warfarin in nonvalvular atrial fibrillation. J Am Heart Assoc. 2016. doi:10.1161/ JAHA.116.003725.

105. Lip GY, Keshishian A, Kamble S, et al. Real-world comparison of major bleeding risk among non-valvular atrial fibrillation patients initiated on apixaban, dabigatran, rivaroxaban, or warfarin. A propensity score matched analysis. Thromb Haemost. 2016;116:975-86.

106. Chan YH, Kuo CT, Yeh YH, et al. Thromboembolic, bleeding, and mortality risks of rivaroxaban and dabigatran in asians with nonvalvular atrial fibrillation. J Am Coll Cardiol. 2016;68:1389-401.

107. Hylek EM, Evans-Molina C, Shea C, Henault LE, Regan S. Major hemorrhage and tolerability of 
warfarin in the first year of therapy among elderly patients with atrial fibrillation. Circulation. 2007;115:2689-96.

108. Apostolakis S, Sullivan RM, Olshansky B, Lip GY. Factors affecting quality of anticoagulation control among patients with atrial fibrillation on warfarin: the SAMe-TT(2)R(2) score. Chest. 2013;144:1555-63.

109. Skov J, Bladbjerg EM, Bor MV, Gram J. SAMeTT(2)R(2) does not predict time in therapeutic range of the international normalized ratio in patients attending a high-quality anticoagulation clinic. Chest. 2014;145:187-8.

110. Poli D, Antonucci E, Testa S, Lip GY. A prospective validation of the SAME-TT2R 2 score: how to identify atrial fibrillation patients who will have good anticoagulation control on warfarin. Intern Emerg Med. 2014;9:443-7.

111. Gallego P, Roldan V, Marin F, Galvez J, Valdes M, Vicente V, Lip GY. SAMe-TT2R2 score, time in therapeutic range, and outcomes in anticoagulated patients with atrial fibrillation. Am J Med. 2014;127:1083-8.

112. Lip GY, Haguenoer K, Saint-Etienne C, Fauchier L. Relationship of the SAMe-TT(2)R(2) score to poor-quality anticoagulation, stroke, clinically relevant bleeding, and mortality in patients with atrial fibrillation. Chest. 2014;146:719-26.

113. Proietti M, Lip GY. Simple decision-making between a vitamin $\mathrm{K}$ antagonist and $\mathrm{a}$ non-vitamin $\mathrm{K}$ antagonist oral anticoagulant: using the SAMe-TT2R2 score. Eur Heart J Cardiovasc Pharmacother. 2015;1:150-2.

114. Roldan V, Cancio S, Galvez J, Valdes M, Vicente V, Marin F, Lip GY. The SAMe-TT2R2 score predicts poor anticoagulation control in AF patients: a prospective 'real-world' inception cohort study. Am J Med. 2015;128:1237-43.

115. Andrade JG, Krahn AD, Skanes AC, Purdham D, Ciaccia A, Connors S. Values and preferences of physicians and patients with nonvalvular atrial fibrillation who receive oral anticoagulation therapy for stroke prevention. Can J Cardiol. 2016;32:747-53.

116. Lahaye S, Regpala S, Lacombe S, et al. Evaluation of patients' attitudes towards stroke prevention and bleeding risk in atrial fibrillation. Thromb Haemost. 2014;111:465-73.

117. Balci KG, Balci MM, Canpolat U, et al. Comparison of health-related quality of life among patients using novel oral anticoagulants or warfarin for non-valvular atrial fibrillation. Anatol J Cardiol. 2015. doi:10.5152/AnatolJCardiol.2015.6334.

118. Potpara TS, Pison L, Larsen TB, et al. How are patients with atrial fibrillation approached and informed about their risk profile and available therapies in Europe? Results of the European Heart Rhythm Association Survey. Europace. 2015;17:468-72.

119. Clarkesmith DE, Pattison HM, Lip GY, Lane DA. Educational intervention improves anticoagulation control in atrial fibrillation patients: the TREAT randomised trial. PLoS One. 2013;8:e74037.

120. Lane DA, Barker RV, Lip GY. Best practice for atrial fibrillation patient education. Curr Pharm Des. 2015;21:533-43.

121. Lane DA, Aguinaga L, Blomstrom-Lundqvist C, et al. Cardiac tachyarrhythmias and patient values and preferences for their management: the European Heart Rhythm Association (EHRA) consensus document endorsed by the Heart Rhythm Society (HRS), Asia Pacific Heart Rhythm Society (APHRS), and Sociedad Latinoamericana de Estimulacion Cardiaca y Electrofisiologia (SOLEACE). Europace. 2015;17:1747-69.

122. Zolfaghari S, Harenberg J, Frolich L, et al. Development of recommendations to continue anticoagulation with one of the two types of oral anticoagulants based on the identification of patients' preference. Semin Thromb Hemost. 2015;41:166-77.

123. Potpara TS, Stankovic GR, Beleslin BD, Polovina MM, Marinkovic JM, Ostojic MC, Lip GY. A 12-year follow-up study of patients with newly diagnosed lone atrial fibrillation: implications of arrhythmia progression on prognosis: the Belgrade Atrial Fibrillation Study. Chest. 2012;141:339-47.

124. Potpara TS, Polovina MM, Licina MM, Marinkovic JM, Lip GY. Predictors and prognostic implications of incident heart failure following the first diagnosis of atrial fibrillation in patients with structurally normal hearts: the Belgrade Atrial Fibrillation Study. Eur J Heart Fail. 2013;15:415-24.

125. Potpara TS, Lip GYH. Oral anticoagulant therapy in atrial fibrillation patients at high stroke and bleeding risk. Prog Cardiovasc Dis. 2015;58:177-94.

126. Gage BF, Waterman AD, Shannon W, Boechler M, Rich MW, Radford MJ. Validation of clinical classification schemes for predicting stroke: results from the National Registry of Atrial Fibrillation. JAMA. 2001;285:2864-70.

127. Piccini JP, Stevens SR, Chang Y, et al. Renal dysfunction as a predictor of stroke and systemic 
embolism in patients with nonvalvular atrial fibrillation: validation of the R(2)CHADS(2) index in the ROCKET AF (Rivaroxaban Once-daily, oral, direct factor Xa inhibition Compared with vitamin $\mathrm{K}$ antagonism for prevention of stroke and Embolism Trial in Atrial Fibrillation) and ATRIA (AnTicoagulation and Risk factors In Atrial fibrillation) study cohorts. Circulation. 2013;127:224-32.

128. Singer DE, Chang Y, Borowsky LH, et alAS. A new risk scheme to predict ischemic stroke and other thromboembolism in atrial fibrillation: the ATRIA study stroke risk score. J Am Heart Assoc. 2013;2:e000250.

129. Chao TF, Lip GY, Liu CJ, et al. Validation of a modified CHA2DS2-VASc score for stroke risk stratification in Asian patients with atrial fibrillation: a nationwide cohort study. Stroke. 2016;47:2462-9. 